\title{
Phytochemical Screening of Root, Stem and Leave Extracts of Terminalia avicennoides
}

\author{
M. Emmanuel ${ }^{1 *}$, A. J. Dadah ${ }^{1}$, A. A. Orukotan ${ }^{1}$, J. Abbah ${ }^{2}$ and I. E. Aigbogun ${ }^{1}$ \\ ${ }^{1}$ Department of Microbiology, Faculty of Science, Kaduna State University, Kaduna, Nigeria. \\ ${ }^{2}$ Department of Pharmacognosy and Drugs Development, Faculty of Pharmaceutical Sciences,
} Kaduna State University, Kaduna, Nigeria.

Authors' contributions

This work was carried out in collaboration among all authors. All authors read and approved the final manuscript.

\section{Article Information}

DOI: 10.9734/ARRB/2019/v32i330088

Editor(s):

(1) Dr. Viduranga Y. Waisundara, Faculty of Applied Sciences, Rajarata University of Sri Lanka, Mihintale, Sri Lanka.

(2) Prof. George Perry, Dean and Professor of Biology, University of Texas at San Antonio, USA.

Reviewers:

(1) Bogumil E. Brycki, Adam Mickiewicz University, Poland.

(2) El Jemli Meryem, University Mohammed V in Rabat, Cadi Ayyad University Marrakech, Morocco.

(3) Sara, Yahaya Galo, Umar Suleiman College of Education, Gashu'a, Yobe State, Nigeria. Complete Peer review History: http://www.sdiarticle3.com/review-history/44435

Original Research Article

Received 24 August 2018

Accepted 29 October 2018

Published 26 July 2019

\begin{abstract}
The phytochemical screening of Terminalia avicennoids was carried out using qualitative method to determine the bioactive compounds present in the plant root, stem and leave extracts. Cooled Maceration method was used for the extraction. Hundred grams $(100 \mathrm{~g})$ of each powder was soaked in $1000 \mathrm{ml}$ of distilled water, allowed to stand for 5 hours. The suspension was agitated after 30 minutes. The filtrate was thereafter separated from residue using No. 1 Whatman filter paper and concentrated using rotary evaporator. The crude extracts were separately kept in a screw capped bottle for further research. The bioactive compound in the plants were detected using AOAC method. The result revealed that alkaloid, flavonoid, tannin, saponins, phenol and glycoside were detected in the plants while steroid was not detected in the plants. Therefore, the presence of these phytocompounds is an indicative that the plant is medicinal and it can be used for the treatment of bacterial and fungal infections.
\end{abstract}

Keywords: Phytoscreening; Terminalia avicennoids. 


\section{INTRODUCTION}

Terminilia avicennoids also known as Combretaceae grow in the savannah region of West Africa [1]. It is called "baushe" in Hausa and "Ungbo" in Adara. The plant is used for the treatment of burn wound infection in humans by the Adara people of North central of Nigeria. The use of the root necesacitated this works to determine the phytochemical composition of the entire plant parts.

The use of medicinal plants in the treatment of diseases has gained popularity and generated special interest in recent times. Herbal preparations are increasingly being used in both human and animal healthcare systems. Diarrhoea is one of the common clinical signs of gastrointestinal disorders caused by both infectious and non-infectious agents leading to serious human and livestock debilitating condition. Herbal medicine has long been recognised as one of the oldest sources of remedies used by humans according [2]. A lot of people in both undeveloped and developing countries still rely on medicinal plants for their daily healthcare needs, in spite of the advancement in modern medicine [3]. Different traditional healing practices globally are designed for either therapeutic or prophylactic use in human or animal diseases. A number of studies carried out in Africa, Asia, Europe, Latin America and North America show that plants are routinely used as a remedy for animal diseases. Historically, it is documented that humans make use of the same herbal preparations that they use to treat their sick animals. In Nigeria, farmers are known to treat animal diseases with herbs before the advent of modern medicine. Traditional medical and veterinary practices remain relevant and vital in many areas in Nigeria [4].

Modern drugs are derivatives of medicinal plants [5]. It is now believed that nature has given the cure of every disease in one way or the other. Plants have been known to relieve various diseases worldwide. Plant-derived substances have recently become of great interest owing to their versatile applications. Today, plant materials play a crucial role in the health sector and many studies revealed plants are good sources of antimicrobials [5]. Medicinal plants are the richest bio-resource of drugs, traditional systems of medicine, modern medicines, nutraceuticals, food supplements, folk medicines, pharmaceutical intermediates and chemical entities for synthetic drugs [6]. The knowledge of the phytocompounds present in extracts is a merit for area of specialisation. The correct identification of the herbal material and the active constituents is crucial to quality control, safety, efficacy, acceptability and possible integration into the national healthcare system of herbal remedies. This study was thus carried out to identify bioactive compounds present in Terminalia avicennoides extracts, which also may be responsible for its antibacterial activity. The plant $T$. avicennoides gained special interest because it has been used traditionally for the treatment of different microbial infection. Aqueous was used due to the fact that it is a universal solvent and most populace in Nigeria that use this plant local usually soaked in cool water and the poultice will be apply on the surface of the wound. Whereas those that used it for the treatment of bacterial infection such diarrhoea soaked the powder in water and the infected person would now drink the suspension, as a result the choice of aqueous became very crucial in the research.

\section{MATERIALS AND METHOD}

\subsection{Collection, Identification and Authentication of the Plant}

The fresh root, stem and leaves of Terminalia avicennoides was collected in July, 2017 from Doka village in Doka District along Kaduna-Abuja express way, Kachia Local Government Area, Kaduna State, Nigeria. It was identified at the Department of Botany, Faculty of Science, Ahmadu Bello University Zaria, with the herbarium number 900239.

\subsection{Preparation of the Plant Material}

The root, stem and leaf Terminilia avicennoides were collected in July, 2017. The grey bark was cleared. All the part of the plant were air-dried and later pulverised with the aid of mortar and pestle into powder form. The powder was packed into a clean plastic container with screw cap for subsequent bench work.

\subsection{Extraction}

Hundred gram of each powder (root, stem and leaf) was soaked in litre of distilled water and allowed to stand for five hours and was agitated after 30 minutes, after which the suspension was macerated. The extracts were successively extracted using aqueous solvent. With the help of 
vacuum evaporator, all the plant extracts were concentrated. Each extract was dried using hotair oven at $45^{\circ} \mathrm{C}$ to a constant mass for further research.

\subsection{Phytochemical Analysis}

The method of Trease and Elvans, [7] was applied for the determination of the presence of phytochemicals. The filtrate obtained from each extraction was tested for alkaloids, saponins, flavonoids, phenol, steroids, tannins and glycosides.

\section{RESULTS}

The phytochemical analysis of aqueous extracts of $T$. avicennoids revealed the presence of alkaloid, flavonoid, tannin, saponins and glycoside while steroid was not detected in the plants.

Table 1. Phytochemical constituents of root, stem and leaf extracts of $T$. avicennoids

\begin{tabular}{llll}
\hline Phytocompounds & Root & Stem & Leaf \\
\hline Alkaloids & + & + & + \\
Flavonoids & + & + & + \\
Tannins & + & + & + \\
Saponins & + & + & + \\
Steroids & - & - & - \\
Phenol & + & + & + \\
Glycosides & + & + & + \\
\hline \multicolumn{2}{r}{ Key: + Detected, - Not Detected }
\end{tabular}

\section{DISCUSSION}

From Table 1, the phytochemical constituents of the plant extracts 'root, stem and leaf' showed the presence of alkaloids, flavonoids, tannins, saponins, glycosides and phenol. Brantner and Grein, [8] also carried out the same research and detected the presence of alkaloids, tannins, saponins and using ethanol. This result indicates that the parts of the plants have active ingredients responsible for the antimicrobial activity. The presence of these secondary compounds makes the plants fits or good for the treatment of bacterial and fungal infections because most therapeutic effects of medicinal plants are traced to the plant constituents and the medicinal actions of these constituents are unique to particular species or family [9]. Also, from the result, it can be deduced that only polar and moderately polar phytocompounds are presence which may be due to the fact that, the extraction was done using a polar solvent (distilled water). It is possible that this plant may have high antimicrobial activity due to the presence of these metabolites. Further study can be done to separate the individual metabolites to test their antimicrobial activity against some pathogenic bacteria to determine their potency.

\section{CONCLUSION AND RECOMMENDA- TION}

Phytochemical composition of the root, stem and leaf extracts of the $T$. avicennoids indicate the presence of six active constituents. The presence of these phytocompounds is an indicative that the plant has should have antibacterial property and it can be used for the treatment of bacterial and fungal infections. Other solvents such as ethanol, methanol, and petroleum ether can be used for extraction so that other phytocompounds can be detected. Further investigation, purification and determination of these promising constituents can be done to assay their antimicrobial activity.

\section{COMPETING INTERESTS}

Authors have declared that no competing interests exist.

\section{REFERENCES}

1. Mann A, Amuptan JO, Oyewale AO, Okogun JI, Ibrahim K. An ethanobotanical survey of indigenous flora for treating tuberculosis and other respiratory diseases in Niger State. Nigeria Journal of Phytomedicine and Therapy. 2007;12:112.

2. Mann A, Ibrahim K, Amupitan AJO, Okoguin Jl. Antimycobacterial activity of some medicinal plants in Africa. Journal of Infectious Diseases. 2009;3(2):44-48.

3. Passalacqua NG, De Fine G, Guarrera PM. Contribution to the knowledge of the veterinary science and of the ethno botany in Calabria region (Southern Italy). Journal of Ethnobiology and Ethnomedicine. 2006; 2:52-53.

4. Ojewole JAO. Evaluation of the analgesic, anti-inflammatory and antidiabetic properties of Sclerocarya birrea (A.Rich.) Hochst. Stem bark aqueous extract in mice and rats. Phytotherapy Research. 2004;18: 601-608. 
5. Abdullahi K, Mann A. Evaluation and antimicrobial activity of Anageissus leiocarpus and Terminilia avicennoides against infectious diseases prevalent in hospital environment in Nigeria. Journal of Microbiology Research. 2012;2(1):6-10.

6. Ncube NS, Afolayan AJ, Okoh AI. Assessment techniques of antimicrobial properties of natural compounds of plant origin: Current methods and future trends. African Journal of Biotechnology. 2008; 7(12):1797-1806.
7. Trease GE, Evans WC. Pharmacology $25^{\text {th }}$ Edition, Balliere and Tyndall, London. 1996;250-546.

8. Brantner A, Grein E. Antibacterial activity of plant extracts used externally in traditional medicine. Journal Ethiopian Pharmacology. 2004;44:3540.

9. Cowan MM. Plant products as antimicrobial agents. Clinical Microbiology Reviews. 1999;12(4):564-582.

(c) 2019 Emmanuel et al.; This is an Open Access article distributed under the terms of the Creative Commons Attribution License (http://creativecommons.org/licenses/by/4.0), which permits unrestricted use, distribution, and reproduction in any medium, provided the original work is properly cited. 